\title{
IMPLEMENTING EMI AT A RUSSIAN UNIVERSITY: A STUDY OF CONTENT LECTURERS' PERSPECTIVES
}

\author{
Elena Belyaeva ${ }^{1}$, Lyudmila Kuznetsova ${ }^{2}$ \\ St. Petersburg State University (SPbU), Russia \\ ${ }^{1}$ E-mail: e.g.belyaeva@spbu.ru \\ ${ }^{2}$ E-mail: ldm.kuznetsova@gmail.com
}

\begin{abstract}
The process of internationalization in the sphere of higher education has been gaining momentum on the global scale since the 1990s, with English becoming its major communication tool. English as a medium of instruction (EMI) in universities has received a fair amount of researchers' attention. However, academic press contains little information on research into EMI in Russia. The aim of this case study was to investigate practices of a Russian university regarding the use of English in teaching specialist disciplines and to explore its EMI lecturers' needs and challenges against the backdrop of the process of internationalization in Russian higher education. The research method applied was a self-administered web-questionnaire; the target group included 72 members of the University faculty who teach their courses through English. The article presents the university's policy on EMI analysis and discussion of one of the key stakeholders'- university lecturers' characteristics and perspectives. The findings reflect the existence of challenges which institutions and staff face in the drive to internationalize, which are similar to those observed in some other countries. Tentative suggestions are offered to ways of addressing the situation and to further investigations of the EMI phenomenon in Russia.
\end{abstract}

Key words: higher education (HE) in Russia; internationalization of HE; English as a Medium of Instruction (EMI); a university's EMI policy; EMI lecturers' needs.

\section{INTRODUCTION}

There is general agreement among the authors writing on the topic that over the last two decades English as a medium of instruction (EMI) in higher education (HE) has become a global phenomenon (Fenton-Smith, Humphreys and Walkinshaw, 2017; Airy et al., 2017; Costa, Coleman, 2013; Hamida et al., 2013). As far back as in the 1990s, the effects of the process of internationalization of higher education in Europe, triggered off by political, economic, cultural developments, began to be discussed and analyzed (Vinke, Snippe and Jochems, 1998: 383). The Bologna Process and creation of the European Higher Education Area accelerated the spread of English as the language of communication in the academia and as an instrument of instruction, leading to the exponential growth in the number of programs taught in English in European universities (Maiworm, Wächter, 2002; Wächter, Maiworm, 2014). The first decade of the $21^{\text {st }}$ century saw major policy changes in Asia, especially in South Korea, China, Vietnam (Kedzierski, 2014; Le DucManh, 2012). The study conducted in 2013-2014 by EMI

Submitted October $15^{\text {th }}, 2018$, accepted for publication November $26^{\text {th }}, 2018$ 
Oxford with the support of the British Council presents information about the current trends in EMI policy in some other parts of the world: Latin America, e.g. Brazil, Colombia, Uganda; Africa: Nigeria, Ethiopia, Zambia; some former countries of the socialist block, such as Bulgaria, Hungary, the Czech Republic; and some former Soviet Union territories: Azerbaijan, Kazakhstan, Ukraine (Dearden, 2014). Dearden reports that in most of these countries educational policies pursued by the governments have supported the spread of EMI over the past 10 years.

Although a relatively new field of research, EMI and a wide range of its various dimensions and institutional environments have already been investigated through a broad range of research designs and methodological approaches. Attitudinal studies based on questionnaires, surveys and interviews have prevailed, exploring a complex range of attitudes towards EMI policy and practice. Many of them have made an important contribution to the global baseline study of the EMI situation, offering insights into various EMI aspects (Brock-Utne, 2007; Wilkinson, 2005; Tange, 2010; Griffiths, 2013; Airey, 2013). Ethnographic studies allow to explore teaching and assessment materials, curricula, syllabi, course outlines and other institutional documents (Klaassen, 2001). Observational studies reveal the challenges both students and teachers experience in the EMI context through the analysis of teacher talk, classroom interaction and student comprehension levels (Klaassen, 2001; Kuteeva, 2014; Goodman, 2014).

Overall, research into EMI policies and issues has been carried out in particular linguistic and cultural contexts with a number of their unique socio-political and economic factors and within a certain educational tradition, for example, in Morocco (Belhiah, 2016), Vietnam (Le DucManh, 2012, Nguyen et al 2016), Sweden (Airey and Kuteeva, 2013), Spain (Muñoz, 2016), South Africa (Clegg, 2001), Kazakhstan (Seitzhanova, Plokhikhand Tsaregorodeva, 2015), Taiwan (Wen-Chun Chen, 2004), Denmark (Werther et al, 2014). Researchers observe and discuss some common challenges which are generally associated with the process of teaching content through English: EMI lecturers' language proficiency, deficits in students' English, level of knowledge acquisition, alternative methodological conventions, quality of interaction in class (Earls, 2016: 80-84). However, authors also conclude that context-specific variables are important and warn against adopting a simplistic single perspective (Baker, Hüttner, 2017). Although certain recommendations that researchers offer may serve to inform decisions about EMI and the process of their implementation in a specific educational setting, many EMI studies demonstrate that context-specific variables are paramount.

The following two studies inspired us to start exploring the situation with EMI at St Petersburg State University ( $\mathrm{SPbU}$ ): one study was the overview of EMI provision worldwide, conducted by the EMI Oxford research centre, and the other one was carried out by Werther et al. and aimed at exploration of Danish university lecturers' perspectives (2014). Who or what is driving EMI implementation and expansion? What are the different currently developed forms of EMI? These and some other questions, raised in the Oxford study (Dearden, 2014: 3), are pertinent to the Russian context as well. Thus, seeking answers to them may help Russian academics to tackle the agenda of internationalization in the local educational setting. The Copenhagen Business School (CBS) project with a focus on those EMI lecturers, who find teaching through English challenging, addresses issues which resonate with Russian academics and discusses measures which might also be applicable at a university in Russia (Werther et al, 2014). 
Thus, a plan of a study on EMI practices in SPbU was conceived and our first research project was implemented in 2017.

\section{EMI IN RUSSIAN HIGHER EDUCATION}

Russia is one of non-Anglophone countries which is about to face a global shift from English being taught as a foreign language to English being the medium of instruction for a wide range of academic subjects. Although there can be found little information focusing specifically on the Russian Federation's agenda regarding EMI, the country has not remained uninvolved in the process of education globalization and, more specifically, internationalization and 'Englishization' of its education (Kovaleva et al, 2015). In October 2009, a new Federal Standard of Primary Education was adopted (Ministry of Education and Science Order \#373) based on which Russian schools started teaching foreign languages, predominantly English, from the second grade onwards. Concurrently, in the sphere of higher education over the last decade there has been a gradual shift towards largest Russian universities increasingly teaching their students more English and offering more undergraduate and, especially, master's degree programs entirely in English.

The proliferation of EMI programs occurs in response to the policy of internationalizing Russian higher education pursued by the Russian government. A major step taken earlier in this direction was the signing of the Bologna Declaration and Russia becoming part of the European Area of Higher Education in 2003. This involved a major transformational change in Russian higher education: restructuring it from a two-level into a three-level degree system, developing new federal standards and entry requirements, accepting the European Credit Transfer System to reflect students' performance. These are but a few most important and readily observable changes. This reform increased international mobility of Russian academics and students, while also raising the number of students from abroad who came to Russian HEIs on exchange programs or, less often, to get a degree.

Among the more recent moves towards internationalizing Russian universities and gaining the competitive edge on the international market of educational services was the government's launch of the so-called " $5-100$ " project in 2012. A number of leading Russian universities participating in the project are provided with federal support to develop themselves into institutions able to meet the world standards and to compete with the international leaders in education. By the year 2020 at least five of the project participants are expected to enter the international ranking list of the world top 100 universities (RF Government's Order \#2006-p, 2012), which according to this document, would boost modernization of Russian higher education, research and development, and would produce a multiplication effect in the whole system. Yet another step in internationalizing Russian HEIs is the 2017 high-priority project "Developing the export potential of the Russian system of education" (site of the Ministry of Education and Science, Projects). It envisages that by the year 2025 export of Russian education services should increase, the enrollment of international students rising from 220,000 people in 2017 to 710,000 in 2025 . Naturally, this may be possible if there are more programs taught in foreign languages. The "Passport" of the aforementioned Project specifically sets "the development and improvement of programs taught in English" as 
one of its primary goals (Passport prioritetnogo proekta, 2017: 6). Thus, Russian HEIs are now assigned to pursue the path of increasing the number of EMI programs and enhancing the existing ones.

The aim of the present study is to study the situation with EMI at the institution enjoying a special status of one of the largest and oldest universities on the Russian educational scene - St Petersburg State University (SPbU) - its policy regarding the use of English as a medium of instruction and lecturers' responses to it. We analyze the university's documents pertaining to internationalization of its programs and the results of the survey of SPbU lecturers who use English to teach their subject-specific courses and kindly volunteered to share their opinions with us.

\section{SPBU PROFILE AND EMI}

Since St Petersburg State University (SPbU) has been selected for this case study, it is essential to give a brief overview of its current policy regarding internationalization and the state of EMI at this institution. In 2010, SPbU adopted and got approved by the Executive Order of the Russian Government the Strategic Plan of its development between the years 2010 and 2020. According to this document, the university's main strategic goal is joining the ranks of the global elite of classical universities and providing academic and scientific support to the state policy of Russia's innovation-based development, also in its capacity of an educational institution enjoying recognition of the global academic community. Some of the steps to be taken on the way to achieving this goal are: internationalization of the university's educational programs, increasing academic mobility of its staff and students, developing international scientific cooperation. Thus, SPbU, in the drive to make its services more attractive to international audiences, is facing the same challenges as many universities world-wide.

One of the major challenges in the process of internationalization, as attested by the experience of multiple HEIs across the world, is adopting English as the language of instruction on a sizeable proportion of universities' programs (Fenton-Smith at al. 2017). Compared with some non-Anglophone universities in Europe, where on average 25 to 28 $\%$ of all university programs are offered as EMI and around $60 \%$ of master programs are taught in English (Airey et al., 2017), an average Russian university has a long way to go to approach a comparable record.

According to the university's internal documents, in 2017 out of 85 bachelor and 158 master degree programs only 15 were taught in foreign languages -12 in English, 2 in German, 1 in French and Spanish, whereas the target set for 2020 is to offer 30 programs in English as the language of instruction. In an attempt to promote the use of English in teaching academic content, the university's administration has been pursuing the policy of introducing more courses in different disciplines to be taught in English. Since 2015, on the order of the university's administration, at least one course on the curriculum of each program has been taught in English to undergraduates in the final year of their studies. According to the records of SPbU Central Office of Educational Programs, in the academic year 2015-2016 SPbU students were taught their specialist subjects in English on 156 courses. We have tried to reach out to the professors involved in teaching their content in English to explore the context in which they work and to identify their needs and concerns. 


\section{RESEARCH Aims AND METHODS}

The rationale behind this study was to try to respond to some questions, posed by Dearden and addressed to the international research community (Dearden, 2014: 3), and to provide a glimpse of a bottom-up perspective on the situation with teaching through EMI at a Russian university.

This research aimed to:

- study the bio-data and profile of the University EMI lecturers,

- explore the professional characteristics of the target group,

- identify the academics' reasons behind teaching their subjects through English,

- investigate the current EMI situation with a focus on a range of issues including the use of Russian, assessment practice, course materials, etc.,

- identify the perceived needs of the EMI lecturers and their ideas of what can make their teaching through English more effective.

One of the favored data collection methods in EMI research so far have been interviews and questionnaires. This study is no exception. The selected research method was an online survey based on self-administered web-questionnaire allowing to check for mutually exclusive responses at the time of filling in and to control the sample of respondents according to the specified attributes. The survey consisted of 12 questions including open, multiple choice and ranking questions. The instrument of data analysis for the purposes of this research was the statistical package SPSS. The online survey was designed in April 2017, and the data collection period was between April and June, 2017. The scope of this study was limited to the SPbU staff teaching their subjects through English. With the assistance of the university's laboratory for sociological and internet research, letters inviting lecturers to participate in the survey were sent to those whose courses were listed in the curricula as taught in English. The response rate was fairly high - 47\%, although not all the questionnaires were fully completed. Our 72 respondents are $\mathrm{SPbU}$ lecturers who are not native speakers of English, who occupy full-time positions in their respective departments and who have not been trained as teachers of English. All the data analysis and the research findings discussion are relevant to this particular HE institution with no good reasons for any generalizations and/or conclusions transfer to other Russian HEI.

\section{RESEARCH RESULTS AND DISCUSSION}

The data collected through the online survey consists of the respondents' answers to the survey questions and presents a SPbU EMI teacher's general profile and the most important attributes of the 72 respondents. All of the university EMI teachers surveyed are non-native speakers of English who learned English as a foreign language at school and/or university. Among the 72 respondents 36 are female, 28 male and 8 people left this question unanswered. As for their age, at the time of the study $54.1 \%$ were 45 or younger, $18 \%$ between 46 and $55,12.5 \%$ over 55 . The most telling figure here is that one third of the sample (33.3\%) are lecturers whose age is $26-35$, which seems to suggest that the level of English language proficiency among the younger members of the profession is more often such as to make them adequately prepared for teaching their subject matter in this foreign language. 
Asked about the subject content they teach, 37 participants (51.4\%) reported teaching the humanities and social sciences, 16 respondents teach natural sciences, 6 respondents teach STEM subjects (science, technology, engineering and mathematics), 2 people teach economics and business, and 1 person reported teaching IT. In 9 questionnaires this item was left unanswered. As the university's recent decision was to offer at least one EMI course to students of baccalaureate in their fourth year at each and every department, the resulting spread of subjects taught in English is the reflection of this policy. Yet another figure reflecting the effect of the administrative decision to introduce an EMI course in the curriculum of all undergraduates is the number of years the surveyed lecturers have taught them: more than a half $(58.4 \%)$ have been doing it for one or two years, plus another $11 \%$ reporting about their three-year EMI experience.

Multiple research projects worldwide studying the EMI phenomenon have analyzed its application in English-only institutions or specific programs taught in English (see, for example, Fenton-Smith et al. 2017, Airey et al. 2017). As mentioned earlier, there are such programs in SPbU, too. Those professors who teach more than two EMI courses would typically work on international programs with audiences consisting of students with the B2 and above level of English proficiency tested at the entry examinations. The fact that $62.5 \%$ of the respondents indicated teaching only one discipline in English is another illustration of the same course of action on the part of the university decisionmakers - the requirement for each bachelor program to offer at least one discipline in the English language. What is not entirely clear is the reasoning behind the decision to implement EMI in teaching a single subject on otherwise Russian medium of instruction programs.

An important universally acknowledged attribute of EMI teachers is their English language qualification. The survey offered to the respondents a multiple choice item where they were asked to tick all the language qualifications they possessed, hence the overall percentage in Fig. 1 below is bound to exceed 100\%. Those having a degree from a university abroad make $12.5 \%$ of the whole, which means that they are likely to have the level of EL proficiency that was sufficient to study in English. The widely shared assumption is that the English language proficiency which allowed them to be educated through English may also be adequate for teaching purposes which is not at all necessarily the case. Only $20.8 \%$ of the respondents have an international language certificate, such as TOEFL, IELTS or Cambridge ESOL, attesting to their level. It should be mentioned, however, that the survey did not ask the lecturers to indicate their score or the language level according to CEFR, thus, we cannot be certain how proficient they are. We can only assume that those $12.5 \%$ of the respondents who graduated from universities abroad had to meet those universities requirements and should be level B2 or above. 


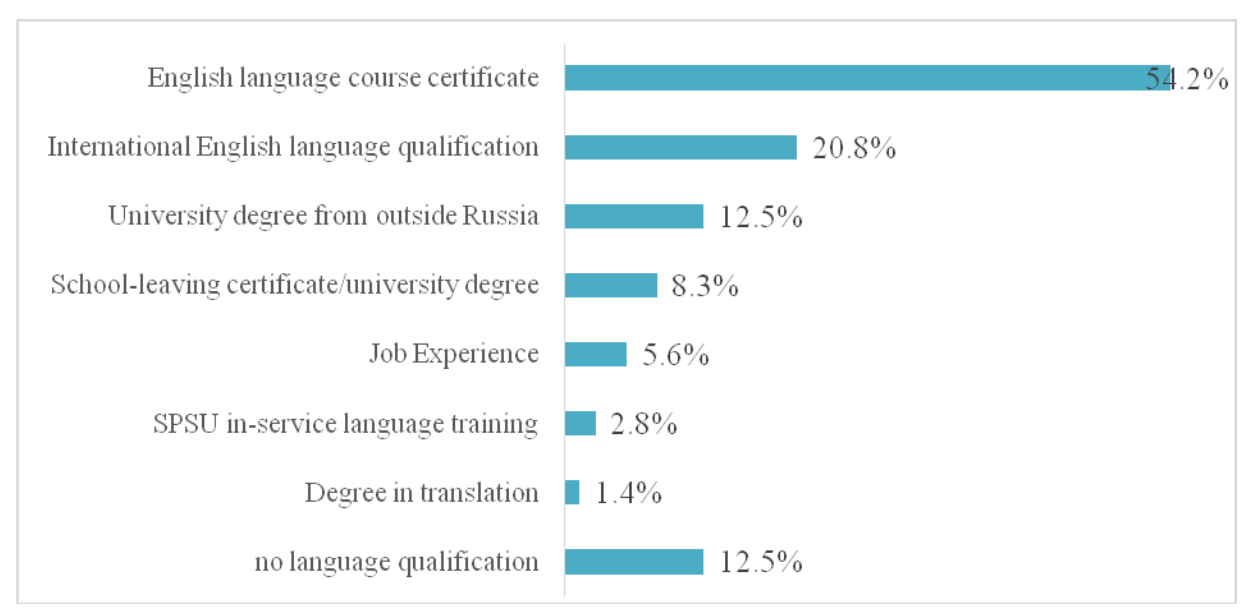

Fig. 1 Respondents' language qualifications (the overall sum is more than $100 \%$ as the respondents could tick more than one option in the multiple choice question)

Unlike a university in Denmark described by Werther et al. (2014), SPbU does not have any selection procedure which would ensure that its EMI staff is language-wise ready to teach their subjects through English. The fact that $54.2 \%$ of the lecturers surveyed have some kind of a language certificate obtained on completing a course in a local language centre and $8.3 \%$ mentioned degrees from Russian universities where EFL is part of the curriculum, cannot with any measure of reliability attest to their level of English. The number of those who received the in-service English language training offered by $\mathrm{SPbU}$ is $2.8 \%$ and it tends to indicate that the language support offered to EMI teachers by their employer is quite limited.

The EMI lecturers' responses to another question of our survey were about other academic purposes they use English for. The overwhelming majority of the staff uses English as a communication tool in order to: write up research and get published $90.3 \%$, present at conferences $-86.1 \%$, work on international research projects $-59.7 \%$. These figures may also be viewed as an indirect indicator of the academics' overall language competence. The quality of the English language these professors possess enables them to perform in English tasks which are fairly challenging even to native speakers of the language. This may be interpreted as evidence that those embarking on the task of writing academic papers in English may have sufficient command of the language to deliver their subjects in it. It is important to mention here that this is not often the case. There is a substantial body of EMI research that finds faculty members who regularly use English for research purposes experience difficulties in the classroom. 


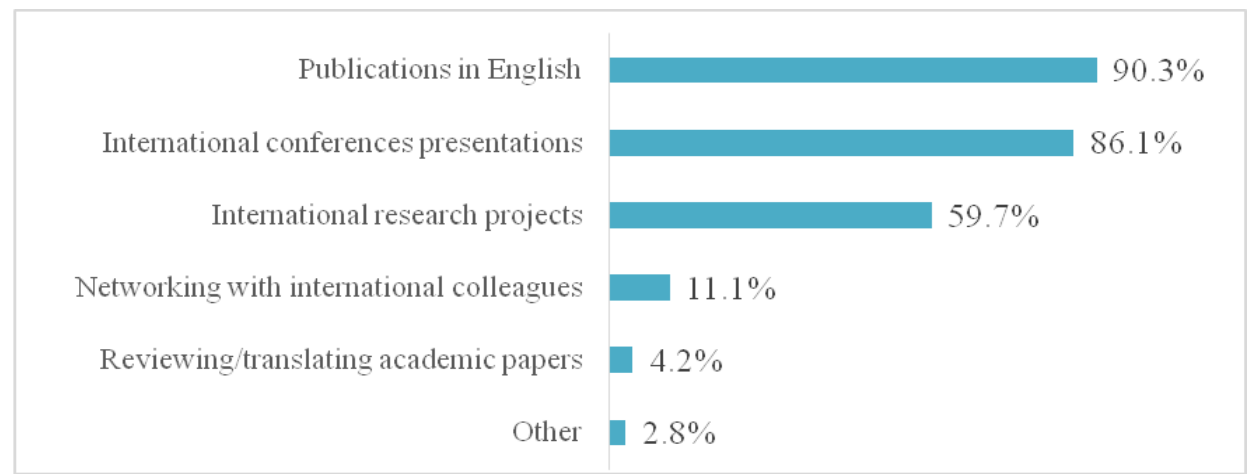

Fig. 2 English language used by the respondents for other than teaching purposes

Some research projects, exploring the situation with EMI in various settings, addressed the issue of instructors' motivation to teach through the medium of English (Whether et al. 2014; Costa and Coleman 2013). The commonest prerequisite for staff getting involved in EMI programs is a change in the university's policy aimed at increasing the internationalization of its programs, as a consequence of which the faculty were compelled to start teaching their subjects in English (Costa and Coleman, 2013: 17). Thus, we were also interested in identifying the reasons behind $\mathrm{SPbU}$ academics switching to EMI. Figure 3 below presents a list from which they were asked to choose any items which apply to them. Not surprisingly, $72.5 \%$ of the respondents stated that it was their department's (their university's) decision. The above group may have been the same lecturers who chose the option saying that they felt their English to be sufficient for teaching their subjects through English - 73.9\%.

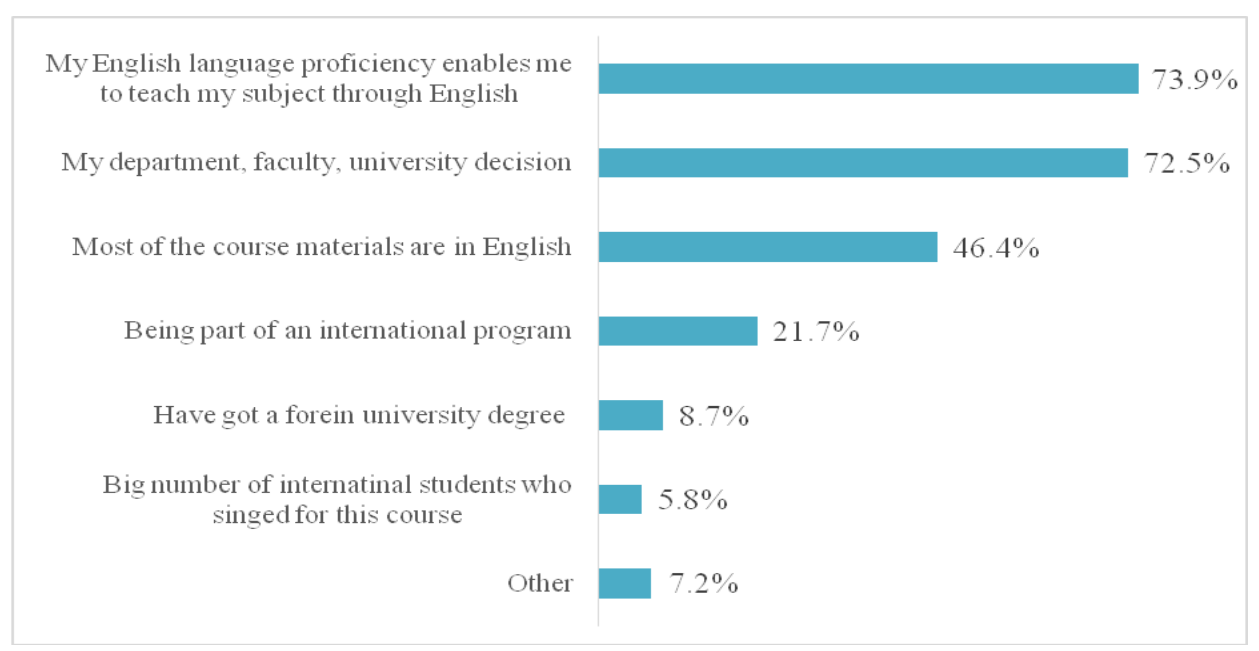

Fig. 3 Reasons behind introducing EMI courses (the overall sum is more than 100\% as the respondents could tick more than one option in the multiple choice question) 
Some of the other factors involving academics in using EMI are: there being a lot of materials in English on their subject (46.4\%), teaching on a collaborative international program (21.7\%), having studied their subjects in English outside Russia (8.7\%), and the growing numbers of international students willing to take courses in English (5.8\%). Some of the lecturers (7.2\%) used a chance to add an option which was not on the list, suggesting that EMI helped develop their students' language proficiency and stressing the need for more EMI courses.

\section{Research Data Describing Emi LeCtuRERs' Challenges AND NeEDS}

It was an important goal of this study to explore EMI lecturers' challenges, so one of the survey items offered a list of questions about the difficulties they face which may hinder the desirable learning outcomes. Not surprisingly, $42 \%$ of our respondents pointed to being unsure about their students' comprehension of the material offered in the English language. EMI lecturers seem not to get sufficient evidence that their students are effectively constructing subject knowledge when the subject matter is presented in a foreign language. A similar concern is expressed by Seitzhanova et al. (2015:77) regarding non-native English speaking students encountering different language problems in their EMI courses in universities of Kazakhstan. The same problem was identified by South Korean researchers (Im and Kim, 2015) who suggested scaffolding EMI instruction through blended learning. Some evidence of there being the same hurdle comes from studies conducted in Taiwan which also highlight the need for more language support for students (Chang, 2010).

About a third of our respondents $(30.4 \%)$ feel the need for adopting a different pedagogical approach, i.e. the necessity to change the teaching routines and classroom practices when conducting classes in English. Similar concerns have been voiced by content teachers in a variety of other universities practicing EMI (Goodman, 2014; Fenton-Smith et al., 2017:201-202). Professional training in teaching through English might help to solve this problem, and this need is felt by $20.3 \%$ of the content lecturers surveyed. This figure is close to the number of those (18.8\%) who stated that they do not have sufficient knowledge of classroom discourse to manage their classes effectively in English and to interact with their students. The subject-related vocabulary does not seem to be a problem but the language of classroom management or English for teaching purposes is what content teachers feel they lack. A somewhat smaller proportion of the respondents (11.6\%) pointed to the challenge of syllabus design and course materials writing in English. In the additional comments slot some of them mentioned the shortage of course books and course materials in English, a wish to get support on the part of English language professionals, a need for upgrading their own English or, conversely, experiencing no difficulties whatsoever. The latter statement was made by only four of our respondents (7\% of the total) as opposed to, for example, $75 \%$ of the EMI lecturers surveyed at a university in Denmark (Werhter et al. 2014: 447). However, quite a few additional comments coming from about $20 \%$ of the whole group reiterated that it is the students' level of English - their insufficient knowledge of subject-related vocabulary and terminology, inability to take part in class discussions and perform interactive tasks, lack of practice in listening to lectures - is what makes their job so challenging. 
The widely discussed issue of the use of L1 in an EMI classroom (Kuteeva, 2015; Belhaih, Elhami, 2015; Dearden, 2014:24) has also come into the focus of this study and the lecturers were asked to indicate the amount of Russian they use in their EMI courses. More than a half - 38 respondents reported that, when lecturing, they use about $10 \%$ of L1 (18 persons) or less than $10 \%$ to none (20 persons); close to $30 \%$ (21 person) resort to Russian in between $25 \%$ and $50 \%$ of classroom teaching; the others have to do it more often. The reason given in additional comments by those who do not use L1 is that they have international students in their audiences. Regarding situations requiring the use of Russian in an EMI classroom, the following classroom contexts were listed as typical and/or frequent:

- introducing new terms and concepts $(38.5 \%)$;

- continuous assessment (29.2\%);

- end-of-the-course assessment (24.6\%);

- presentation slides and course handouts (13.8\%);

- course material revision (7.7\%);

- key terms translation $(6.2 \%)$;

- problem solving tasks $(4.6 \%)$.

Respondents' additional comments contained the following suggestions regarding the minimization of L1 use on EMI courses: to provide the students with textbooks and course materials in English; to increase the amount of English language teaching for the students prior to offering them courses in English helping students to get rid of all their inhibitions and to overcome their fears and concerns about their low language proficiency; to provide the students with native speaker teachers of English.

The backwash effect of the end-of-the-course examination format is quite powerful and, therefore, this study also aimed at identifying the most widely used final assessment formats. The findings indicate that $53.1 \%$ of the respondents use written tests with open questions in English; $35.9 \%$ reported using written examination with multiple-choice and matching type of questions in English. Below $43.8 \%$ of the respondents use oral testing in English and $12.5 \%$ administered the final oral test in Russian. The percentage total amounting to more than $100 \%$ indicates that lecturers use a combination of testing formats, and here we can also speak about the reverse backwash effect: that of the language of instruction influencing the methods of assessment. For a long time the traditional form of end-of-course assessment at Russian universities was that of students' oral answers to examiners' questions. The adoption of the English language to teach subject-specific courses seems to have had an impact on the ways final assessment started to be conducted, primarily on EMI programs, with written tests gradually ousting traditional oral examinations.

It has been mentioned earlier that all the lecturers surveyed are not native speakers of English, so it seemed important to explore what resources they used while preparing to teach their subjects through English. There was a multiple choice question in responding to which they could tick any number of materials they used in preparing their courses and teaching them. The most common ones among those were academic articles from international journals (most often used by about $74 \%$ of the lecturers) and course books in English which 50\% reported using most of the time, with $22 \%$ of the lecturers, however, not using the latter at all. The reason for this was given in responses about the difficulties SPbU professors face regarding shortage of course books in English available to them. The range of other resources mentioned by our respondents in their free 
comments turned out to be quite wide - from all kinds of internet resources: international companies' websites, international bloggers' sites, authentic subject-related materials, international conference materials online, case studies, videos of English speaking professors, etc. - to their own publications in English and MOOC's materials they had used earlier. Two respondents reported their English native speaker colleagues' help and support.

Perhaps, the most important answers we wanted to get as a result of the survey were to the question about what can help our university's lecturers in teaching their subjects through English. The list of suggested options contained:

- English language course materials for the teachers and students,

- Working together with language teachers and getting consultations from language specialists,

- In-service English language training for the lecturers,

- Gate-keeping for the students' language level which should be B2,

- Preparatory English language course for the students,

- University teaching methodology guidance for EMI teachers.

Clearly, the majority of the surveyed content lecturers believe the English language proficiency to be the key success factor. Not surprisingly, about half of them listed as top priority (under \#\# 1 and 2) their students' language proficiency - its level no lower than B2 and/or a preparatory English language course for them. Second in the lecturers' rating was the English language training for the lecturers and support of the English language professionals. Among the less urgent needs there were reported methodological guidance and supply of the teaching materials in English (10\% and 9\% of respondents respectively find them top priority issues). In their additional comments the respondents suggest to improve the students' and lecturers' language quality, to increase the proportion of international students in groups and cooperation with colleagues from universities abroad, to provide better financial motivation to EMI faculty and to reduce bureaucracy and administrative control. It should also be noted here that in contrast to what Costa (2015: 133) reports in her overview of both linguistic and methodological EMI training in a number of non-English-speaking European countries, where some universities have started providing lecturer training, EMI teachers in SPbU have been offered little language training support before embarking on the task of lecturing in English. The lack of training for lecturers, who are encouraged to teach their subjects through English, has also been discussed earlier by Airey (2011: 44) and some other authors (Floris 2014; Nguyen et al. 2017).

\section{IMPLICATIONS}

Based on the above mentioned findings, it appears that an institutional language policy statement could provide an overall framework with the priority aims and objectives around which all the university staff could unite their efforts. Having examined EMI lecturers' views, it seems necessary to introduce professional development programs aimed at developing and supporting EMI teachers (focusing on fluent classroom discourse, interactive teaching style, course design and materials development) in a variety of modes: face-to-face; online; the combination of the two; group mode and tailor made individual consultations. 
In the effort to raise the country's export potential and with growing numbers of international students, EMI teachers need to be prepared for evolving internationalization and globalization. Therefore, EMI teachers could also be assisted to develop their intercultural competence which, unfortunately, at the moment is not a perceived need at all.

There are clearly no ready solutions among the shared and published expertise abroad for the Russian HEI context. We need some local solutions with all the complexity of the local factors in view. There is clearly a need for a systemic approach to human resources development and management in Russian universities. Important as they are, it cannot be reduced to professional development programs for university teachers to develop all the required competencies to teach in English, it should also include staff selection, performance appraisal and quality control systems as well. It appears necessary to cultivate an organizational competence to develop syllabi together with a bank of teaching resources in English at the institutional level. There should also be more extensive educational exchange for university lecturers providing them with opportunities to teach internationally.

\section{CONCLUSIONS}

The present study explored the practices of a Russian university regarding the use of English in teaching specialist disciplines, and the investigated case of St Petersburg State University offers some convincing evidence of $\mathrm{HE}$ internationalization. However, compared to many other countries with a lot of hands-on experience of EMI, Russia is definitely still at the very beginning of its EMI journey.

The SPbU case indicates that a university in Russia may typically offer a few programs in English, but most of its programs are taught through Russian, and the growth of EMI in Russian HE is somewhat imposed on the Russian Academia. The notion of 'internationalizing universities' in Russia is currently often conceived in the narrow sense of attracting foreign students and in some institutions also as attracting and employing international teaching staff. This study illustrates a case of EMI being introduced through a top-down approach with an agenda to increase the export potential of a particular university.

Another task of this study was to explore EMI lecturers' needs and challenges through a self-administered web-questionnaire, and the findings reflect the existence of challenges which institutions and staff face in the drive to internationalize, which are similar to those observed in some other countries. Similar to many other countries, where English has been long taught as a foreign language, EMI implementation at the tertiary level is getting little support. Hence, there is a shortage of linguistically qualified university lecturers; there is a lack of resources and guidelines for teaching and assessment; there is no pedagogical or language support to EMI teachers; there are concerns about the quality of learning outcomes.

EMI university lecturers in Russia are facing a number of serious challenges and, unfortunately, some EMI university lecturers still believe that EMI is just a matter of translating their course materials and slides from Russian into English and then delivering their courses in a teacher-led style. However, the most typical excuse behind the dominant lecture mode is students' low language proficiency leading to various inhibitions which do not allow them to contribute and to participate. 
The investigated case study of the EMI phenomenon in a Russian university does not intend to suggest any generalizations and projections upon the tendencies in the whole of Russian HE but rather offers a glimpse of a number of current trends.

Acknowledgments. The authors would like to thank the St Petersburg State University "Centre for Sociological and Internet Research" which was opened in 2013 and since then has been offering methodological and technical support of the software and hardware application to all SPbU researchers working in various fields beyond sociology.

\section{REFERENCES}

Airey, J., Lauridsen K.M., Räsänen A., Salö L., Schwach V. 2017. The expansion of English-medium instruction in the Nordic countries: Can top-down university policies encourage bottom-up disciplinary literacy goals? Higher Education, 73, 561-576.

Airey, J. 2013. "I don't teach language". The linguistic attitudes of physics lecturers in Sweden. AILA Review, 25(5), pp. 64-79.

Baker, W., and Hüttner J. 2017. English and more: a multisite study of roles and conceptualisations of language in English medium multilingual universities from Europe to Asia. Journal of Multilingual and Multicultural Development, 38:6, 501516, DOI: 10.1080/01434632.2016.1207183

Belhiah, H. 2016. English as a Medium of Instruction in Moroccan Higher Education, Arab World English Journal, December 2016, pp. 227-238.

BelhiahH., Elhami M. 2015. English as a medium of instruction in the Gulf: When students and teachers speak. Language Policy, 14, pp. 3-23

Brock-Utne, B. 2007. Language of instruction and student performance: new insights from research in Tanzania and South Africa. International Review of Education, 53 (5- 6), pp. 509-530

Chang, Y. 2010. English medium instruction for subject courses in tertiary education: reactions from Taiwanese undergraduate students. Taiwan International ESO Journal, 2 (1), pp. 44-84

Clegg, J. 2001. Towards successful English-medium education in South Africa, in D. Marsh (ed.), Enhancing English-medium Education in Namibia. Jyväskyla: University of Jyväskyla, pp. 11-13

Costa F., Coleman J.A. 2013. A survey of English-medium instruction in Italian higher education. International Journal of Bilingual Education and Bilingualism, v.16 (1), pp.3-19.

Costa F. 2015. English Medium Instruction (EMI) Teacher Training Courses in Europe, in Recognizioni. Rivista di lingue, letterature e culture modern, vol. 2., No 4, pp. 127-135

Dearden, J. 2015. English as a medium of instruction - a growing phenomenon. www.teachingenglish.org.uk

Doiz A., Lasagabaster D., Sierra L.M., eds. 2012. English-Medium Instruction at Universities: Global Challenges. Channel View Publication.

Earls C. W. 2016. Evolving Agendas in European English-Medium Higher Education: Interculturality, Multilingualism and Language Policy. London: Palgrave Macmillan. 
Fenton-Smith,B. et al. (eds.), 2017. English Medium Instruction in Higher Education in Asia-Pacific, Multilingual Education 21, DOI 10.1007/978-3-319-51976-0_3

Floris F.D. 2014. Learning subject matter through English as the medium of instruction: students' and teachers' perspectives. Asian Englishes, vol. 16, No 1, pp. 47-59.

Goodman B. A. 2014. Implementing English as a medium of instruction in a Ukrainian University: Challenges, adjustments, and opportunities, International Journal of Pedagogies and Learning, 9:2, 130-141, DOI: 10.1080/18334105.2014.11082026

Griffiths, E. 2013. English as a medium of higher education institution in Norway: A critical exploratory study of lecturers' perspectives and practices ( $\mathrm{PhD}$ Thesis). University of Exeter.

Jenkins, J. 2014. English as a lingua franca in the international university: the politics of academic English language policy. London: Routledge.

Jin-HyokIm and Jeongyen Kim 2015. Use of Blended Learning for Effective Implementation of English-Medium Instruction in a Non-English Higher Education Context. International Education Studies: Vol. 8, No. 11, pp.1-15

Kedzierski M. 2016. English as a medium of instruction in East Asia's higher education sector: a critical realist Cultural Political Economy analysis of underlying logics. Comparative Education, vol.56, No 3, 375-391.

Kirkgos Y. 2009. Students' and lecturers' perceptions of the effectiveness of foreignlanguage instruction in an English-medium university in Turkey. Teaching in higher education, vol. 14, number 1, 81-93

Klaassen, R. 2001. The international university curriculum: challenges in English-medium engineering education (Doctoral dissertation). Technische Universiteit Delft, Delft, NL. http://repository.tudelft.nl/view/ir/uuid\%3Adea78484-b8c2-40d0-9677-6a508878e3d9

Kuteeva, M. 2014. The parallel language use of Swedish and English: The question of 'nativeness' in university policies and practices. Journal of Multilingual and Multicultural Development, 35(4), pp. 332-344.

Kuteeva, M. and Airey, J. 2014. Disciplinary differences in the use of English in higher education: reflections on recent language policy developments in Higher Education (2014), 67, 5: pp. 533-549

Le DucManh. 2012. English as a Medium of Instruction at Tertiary Education System in Vietnam. The Journal of Asia TEFL, Vol. 9, No. 2, pp. 97-122.

Maiworm, F. and Wächter, B. 2002. English-language-taught degree programmes in European higher education, Trends and success factors. ACA papers on International Cooperation in Education. Bonn: Lemmens Verlags \& Mediengesellschaft.

Marsh, D. 2006. English as a medium of instruction in the new global linguistic order: Global characteristics, Local Consequences, in Proceedings of the Annual Conference for METMaC, 2: pp. 29-38

Munoz, A.J. 2015. English as a medium of instruction: Evidence for language and content targets in bilingual education in Economics in International Journal of Bilingual Education and Bilinguialism, 19, 5. http://www.tandfonline.com/doi/10.1080/13670050/ 2015.1125847

Nguyen T.H., Walkinshaw I., Pham H.H. 2017. EMI Programs in a Vietnamese University: Language, Pedagogy and Policy Issues. In B. Fenton-Smith et al. (eds.), English Medium Instruction in Higher Education in Asia-Pacific, Multilingual Education 21, DOI 10.1007/978-3-319-51976-0_3 
Obaidul Hamida M., HoaThi Mai Nguyenb and Richard B. Baldauf Jr. 2013. Medium of instruction in Asia: context, processes and outcomes in Current Issues in Language Planning, Vol. 14, No. 1, 1-15

Seitzhanova A., Plokhikh R., Baiburov R. and Tsaregorodtseva A. 2015. English as the medium of instruction: Modern tendency of education in Kazakhstan. Internationalization in Higher Education: Management of Higher Education and Research: Vol. 3, issue 1, May 2015, pp. 74-77

Shaw, P. 2013. Adjusting practices to aims in integrated language learning and disciplinary learning. La pédagogie de 1/EMILE en questions. Rechercheetpratiquespédagogiquesenlangues de spécialité - Cahiers de l'APLIUT, 32 (3), 16-29.

Tange, H. 2010. Caught in the Tower of Babel: University lecturer's experiences with internationalization. Language and Intercultural Communication, 10(2), pp.137-149.

Vinke, A.A., J. Snippe\& W. Jochem. 1998. English-medium content courses in nonEnglish higher education: a study of lecturer experiences and teaching behaviours. Teaching in Higher Education, 3: 383-394.

Wächter, B., and F. Maiworm, eds. 2014. English-taught Programmes in European Higher Education: The State of Play in 2014. Bonn: LemmensMedien GmbH

Wen-Chun Chen. 2004. Proficiency as a Factor in English-Medium Instruction Online Tutoring, English Language Teaching; Vol. 7, No. 3: pp. 134-149

Werther, Ch., Denver, L., Jensen, Ch. and Mees, I.M. 2014. Using English as a medium of instruction at university level in Denmark: the lecturer's perspective, in Journal of Multilingual and Multicultural Development, Vol. 35, No. 5, pp. 443-462

Westerholm, K., \&Räsänen, A. 2015. Sharing and promoting disciplinary competences for university teaching in English: voices from the University of Jyväskylä language centre's TACE programme. In J. Jalkanen, E. Jokinen, \& P. Taalas (Eds), Voices of pedagogical development - Expanding, enhancing and exploring higher education language learning Dublin: Research-publishing.net. (pp. 131-157). doi:10.14705/rpnet.2015.000290

Wilkinson, R. 2005. The impact of language on teaching content: Views from the content teacher. Presented at the Bi and Multilingual Universities - challenges and Future Prospects Conference. 